\title{
High Quality of Piezoelectric Response of Nano Ni Doped $\mathrm{Pb}_{1-x} \mathrm{Ni}_{x} \mathrm{TiO}_{3}$ Ceramic
}

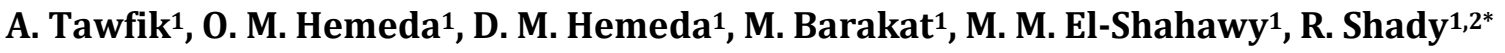 \\ ${ }^{1}$ Department Physics, Faculty of Science, Tanta University, Tanta, Egypt \\ ${ }^{2}$ Department Physics, Oklat Al-Skoor College of Science \& Arts, Qassim University, Qassim, Kingdom of Saudi Arabia \\ Email:omhemeda@yahoo.com, *rehamshadi81@gmail.com
}

How to cite this paper: Tawfik, A., Hemeda, O.M., Hemeda, D.M., Barakat, M., El-Shahawy, M.M. and Shady, R. (2016) High Quality of Piezoelectric Response of Nano Ni Doped $\mathrm{Pb}_{1-\mathrm{x}} \mathrm{Ni}_{\mathrm{x}} \mathrm{TiO}_{3}$ Ceramic. Journal of Applied Mathematics and Physics, 4, 1879-1888.

http://dx.doi.org/10.4236/jamp.2016.410190

Received: September 8, 2016

Accepted: October 15, 2016

Published: October 19, 2016

Copyright $\odot 2016$ by authors and

Scientific Research Publishing Inc.

This work is licensed under the Creative

Commons Attribution International

License (CC BY 4.0).

http://creativecommons.org/licenses/by/4.0/

\section{Abstract}

A series of $\mathrm{Pb}_{1-\mathrm{x}} \mathrm{Ni}_{\mathrm{x}} \mathrm{TiO}_{3}(\mathrm{x}=0,0.1,0.2,0.3,0.4$ and 0.5$)$ were prepared by the general ceramic and co-precipitation method. The grain size decreased with increasing $\mathrm{Ni}$ contents. The piezoelectric modulus $\mathrm{d}_{33}$ increased with increasing Ni contents. It was observed also the $\mathrm{d}_{33}$ of the nanocomposite $\mathrm{Pb}_{1-\mathrm{x}} \mathrm{Ni}_{\mathrm{x}} \mathrm{TiO}_{3}$ prepared by co-precipitation method is higher than those of the prepared by general ceramic method. The coupling factor $k_{p}$ increased by the more doping of $\mathrm{Ni}$. The ultrasonic wave velocity decreased also with increasing $\mathrm{Ni}$ contents. The polarized nano-sample of composition $\mathrm{Pb}_{0.5} \mathrm{Ni}_{0.5} \mathrm{TiO}_{3}$ is suitable for improving application of useful piezoelectric technology.

\section{Keywords}

Piezoelectric Ceramics, $\mathrm{d}_{33}$ Coefficient, Electromechanical Coupling Factor $\mathrm{K}_{\mathrm{p}}$

\section{Introduction}

Lead titanate PT ceramics modified by rare earth elements and alkaline earth elements have emerged as highly promising materials for several piezoelectric applications. This is due to existence of large electromechanical anisotropy in the coupling factors along and transfers direction of polarization [1]-[3].

Samarium modified PT ceramics are reported to exhibit best electric feature [4], [5]. In calcium, modified PT ceramics grain size and porosity is found to affect the behavior of permittivity and planar thickness frequency constant [6]. Additional of strontium in calcium modified PT ceramics increases piezoelectric anisotropy [7], [8]. By substitution of isovalent $\left(\mathrm{Ca}^{2+}, \mathrm{Ba}^{2+}, \mathrm{Cd}^{2+} \ldots\right.$ etc. $)$ ions into the $\mathrm{Pb}^{2+}$ sites, the lattice anisotropy is reduced [9], [10] and the samples become more dense result in a relatively large 
thickness electromechanical coupling coefficient.

In the present work, a comparison between the piezoelectric modulus $d_{33}$ and the electromechanical coupling factor $k_{p}$ for polarized tablets of $\mathrm{Pb}_{1-\mathrm{x}} \mathrm{Ni}_{\mathrm{x}} \mathrm{TiO}_{3}$ prepared by the usual ceramic method and those prepared by co-precipitation method. It is expected that the nano $\mathrm{Pb}_{1-\mathrm{x}} \mathrm{Ni}_{\mathrm{x}} \mathrm{TiO}_{3}$ ceramics will have a pronounced characteristic of $\mathrm{d}_{33}$ and $k_{p}$ than those of published data. This purpose can help in the improved technology.

\section{Experimental}

A series of $\mathrm{Pb}_{1-\mathrm{x}} \mathrm{Ni}_{\mathrm{x}} \mathrm{TiO}_{3}(\mathrm{x}=0,0.1,0.2,0.3,0.4$ and 0.5$)$ were prepared by the usual ceramic method. The raw materials were presenter at $800^{\circ} \mathrm{C}$ for 2 hours. The samples were in the form of tablets and then to be cooled gradually to room temperature.

A second series of $\mathrm{Pb}_{1-\mathrm{x}} \mathrm{Ni}_{\mathrm{x}} \mathrm{TiO}_{3}(\mathrm{x}=0,0.1,0.2,0.3,0.4$ and 0.5$)$ were prepared using co-precipitation method. The chemical reagent were titanium chloride $\left(\mathrm{TiCl}_{3} .15 \mathrm{H}_{2} \mathrm{O}\right)$ nickel (II) chloride, $\left(\mathrm{NiCl}_{2} \cdot 6 \mathrm{H}_{2} \mathrm{O}\right)$, lead chloride $\left(\mathrm{PbCl}_{2}\right)$ and sodium hydroxide $(\mathrm{NaOH})$. All the chemical reagents were dissolve in to $200 \mathrm{ml}$ of distilled water. After mixing and stirring solutions for 6 hours, chemical precipitation was achieved at room temperature vigorous stirring by adding of $\mathrm{NaOH}$ solution gradually the reaction system keep at $80^{\circ} \mathrm{C}$ for 2 hours and $\mathrm{PH}$ solution \pm 12 . After the system cooled to room temperature, the precipitates were washed with distilled water until PH-7. Finally the samples dried in oven at $200^{\circ} \mathrm{C}$ for several hours and sintered at $1000^{\circ} \mathrm{C}$ for 2 hours then left to be cooled gradually with the rate $50^{\circ} \mathrm{C} / \mathrm{hr}$.

The samples were examined by X-ray diffraction using a Philips model (PW-1729) diffractometer with $\mathrm{Cu}-\mathrm{K} \alpha$ radiation $\left(\lambda=1.541 \mathrm{~A}^{\circ}\right)$.

The microstructure of the sintered samples examined using SEM and TEM model Quanta 250 FEG (Field Emission Gun) attached with EDX unit (Energy Dispersive X-ray Analyses), with accelerating voltage 30 K.V., magnification 14x up tp 100,000 and resolution for Gun. 1n. FEI company, Netherlands EMITECH K550X sputter coate England and (JOEL-100SX) and HRTEM model (High Resolution Transmission Electron Microscope JOEL EM 2-100) respectively. The prepared tablets with silver electrodes were polarized by exposing to $2 \mathrm{KV}$ per min at $150^{\circ} \mathrm{C}$ for 1 Hour and then the tablets were left to be cooled under applying the dc field.

The piezoelectric modulus $d_{33}$ was determined by taking the slope of the charge depended of the applied stress.

The coupling factor $k_{p}$ was estimated from the resonance frequency $f_{r}$ and antiresonance frequency $f_{a}$ for the radial mode of vibration [4], [5]:

$$
k_{p}=\sqrt{\frac{2.55 *\left(f_{a}-f_{r}\right)}{f_{r}}}
$$

The ultrasonic wave velocity $C$ was determined from the relation:

$$
f_{r}=\frac{C}{2 \pi a}
$$

where $a$ is radius of polarized tablets. 


\section{Results and Discussion}

Room temperature XRD patterns of the sintered tablets of $\mathrm{Pb}_{1-\mathrm{x}} \mathrm{Ni}_{\mathrm{x}} \mathrm{TiO}_{3}$ for the two methods of preparation are shown in Figure 1. These have sharp and single diffraction peaks, indicating better homogeneity and crystallization of the samples. All the reflection peaks were indexed and correlated with JCPDS card file number 70 - 4057 showing the perovskite structure for all composites. The average particle size $D$ was determined from the half width of the stronger reflections of X-ray using Scherer's equation:

$$
D=\frac{0.9 \lambda}{\beta \cos \theta}
$$

where $\lambda$ is the wavelength of the $\mathrm{X}$-ray for $\mathrm{Cu}-\mathrm{K} \alpha$ radiation $\left(\lambda=1.541 \mathrm{~A}^{\circ}\right)$ and $\beta$ is the full width at half maximum of the peak.

The particle size determined from X-ray diffraction for all samples using Scherer's equation are found to be close nearly to be found from TEM micrographs as shown in Table 1, Figure 1 and Figure 2.

Figure 3 shows the scanning electron micrographs (SEM) of sintered and co-precipitation method of $\mathrm{Pb}_{1-\mathrm{x}} \mathrm{Ni}_{\mathrm{x}} \mathrm{TiO}_{3}$ indicate homogenous distribution of grain brought out the surface of material. The average grain size calculated from micrograph of $\mathrm{PbTiO}_{3}$ is $0.25 \mu \mathrm{m}$. As $\mathrm{Ni}^{2+}$ concentration increases the grain size decreases as given in Table 1. Figure 2 shows the transmission electron micrographs (TEM) of the usual

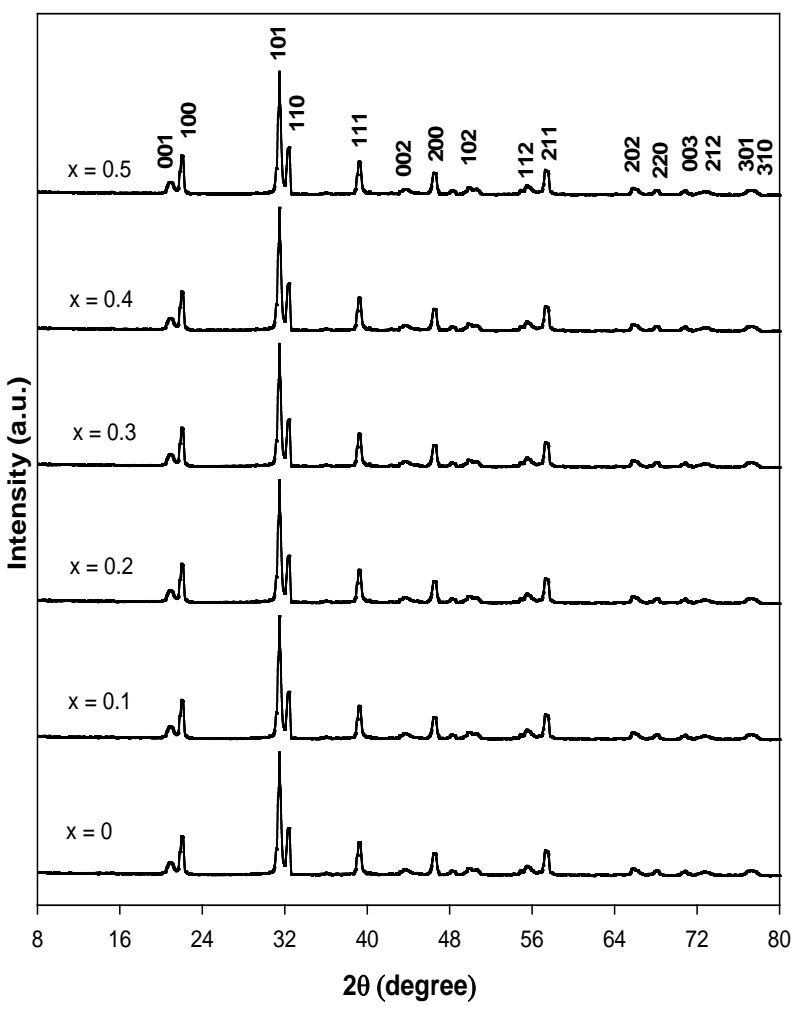

(a)

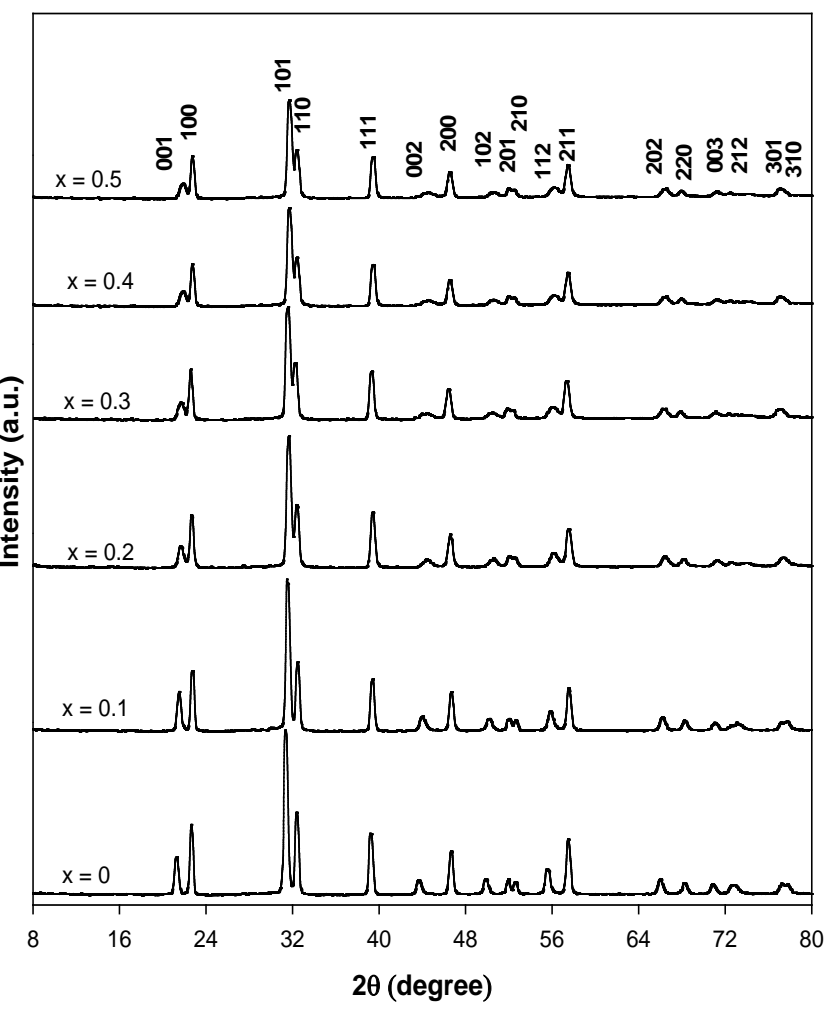

(b)

Figure 1. XRD pattern of " $\mathrm{Pb}_{1-\mathrm{x}} \mathrm{Ni}_{\mathrm{x}} \mathrm{TiO}_{3}$ " system for different ratios of $\mathrm{Ni}$ content $\mathrm{x}$, for (a) Ceramic method; (b) co-precipitation method. 
Table 1. Indicates the value of particle size of $\mathrm{Pb}_{1-\mathrm{x}} \mathrm{Ni}_{\mathrm{x}} \mathrm{TiO}_{3}$ for 1) usual method and 2) co-precipitation method.

\begin{tabular}{ccc}
\hline & \multicolumn{2}{c}{ Particle size $(\mathrm{nm})$} \\
\cline { 2 - 3 } & P.S1 & P.S2 \\
\hline 0.0 & 60.359 & 28.417 \\
0.1 & 55.337 & 27.044 \\
0.2 & 44.274 & 20.478 \\
0.3 & 42.17 & 20.435 \\
0.4 & 37.959 & 18.605 \\
0.5 & 35.92 & 18.949 \\
\hline
\end{tabular}
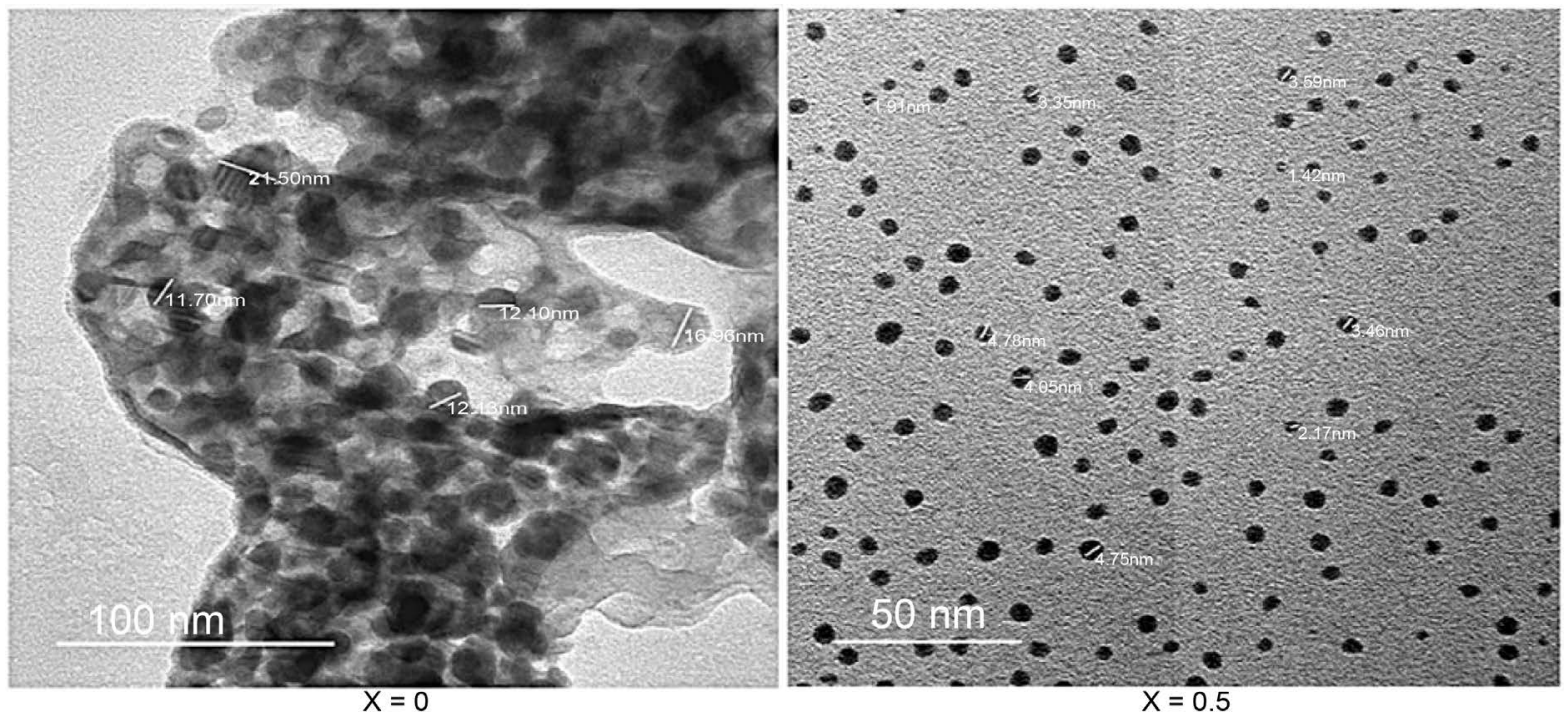

(a)
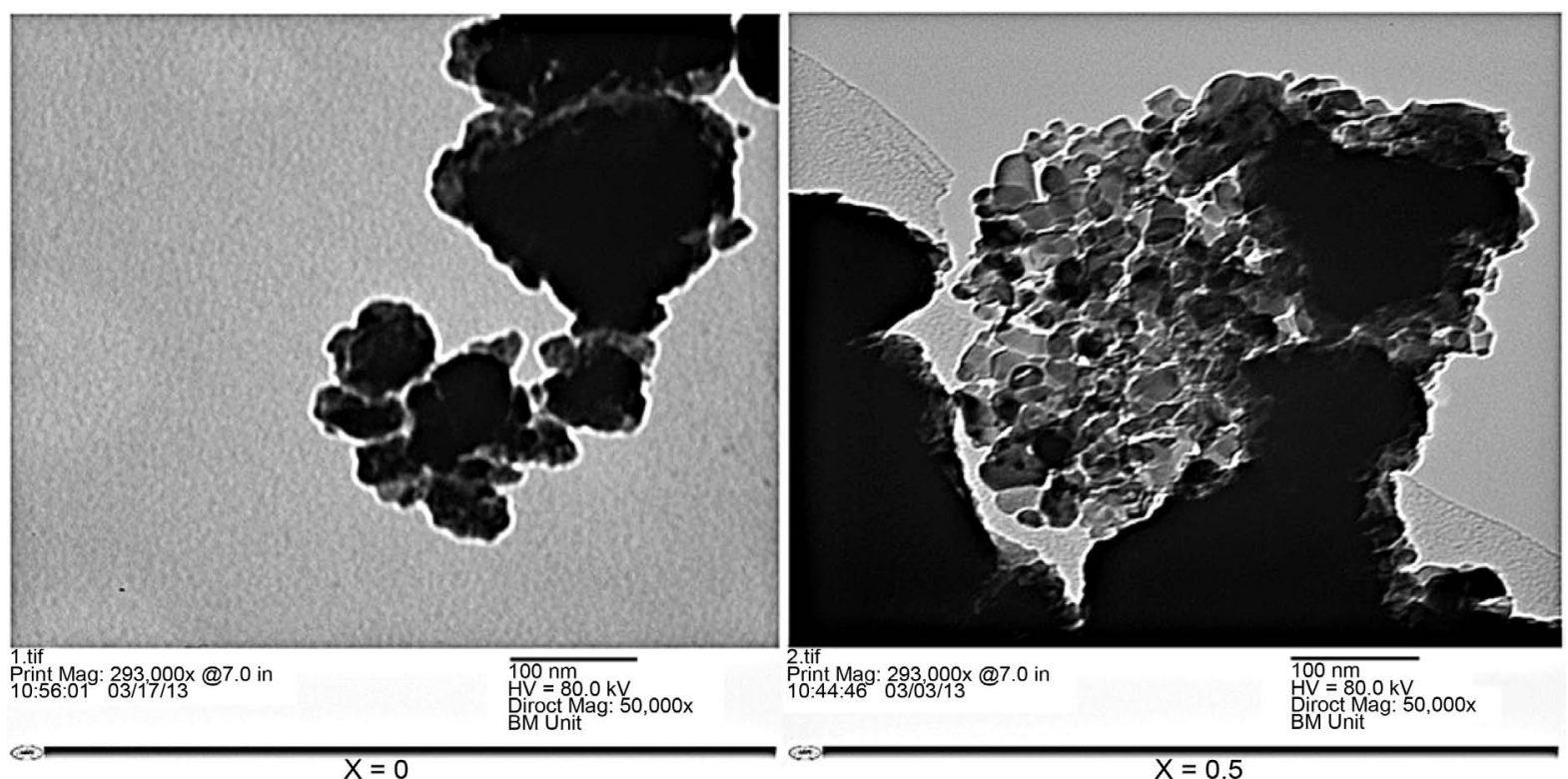

(b)

Figure 2. (a) TEM of co-precipitation $\mathrm{Pb}_{1-\mathrm{x}} \mathrm{Ni}_{\mathrm{x}} \mathrm{TiO}_{3}$ samples; (b) TEM of ceramic $\mathrm{Pb}_{1-\mathrm{x}} \mathrm{Ni}_{\mathrm{x}} \mathrm{TiO}_{3}$ samples. 

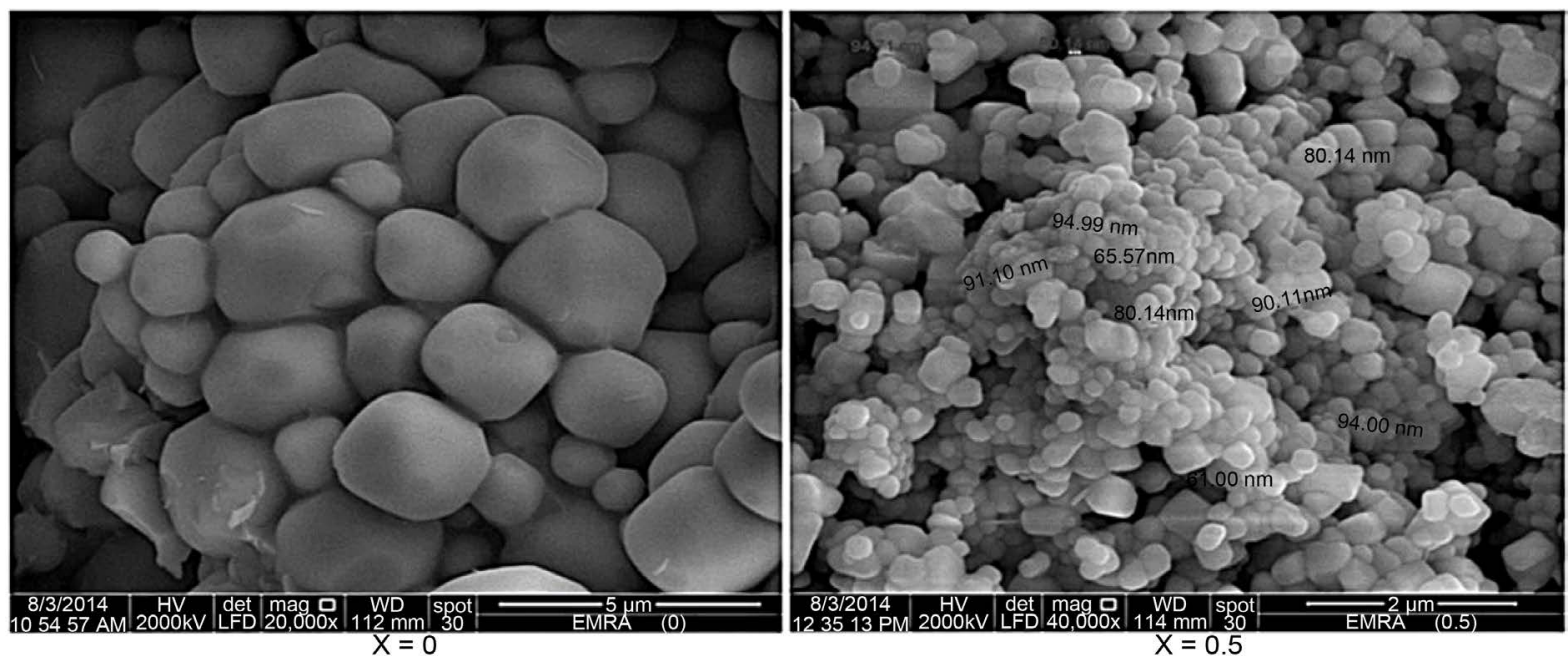

(a)

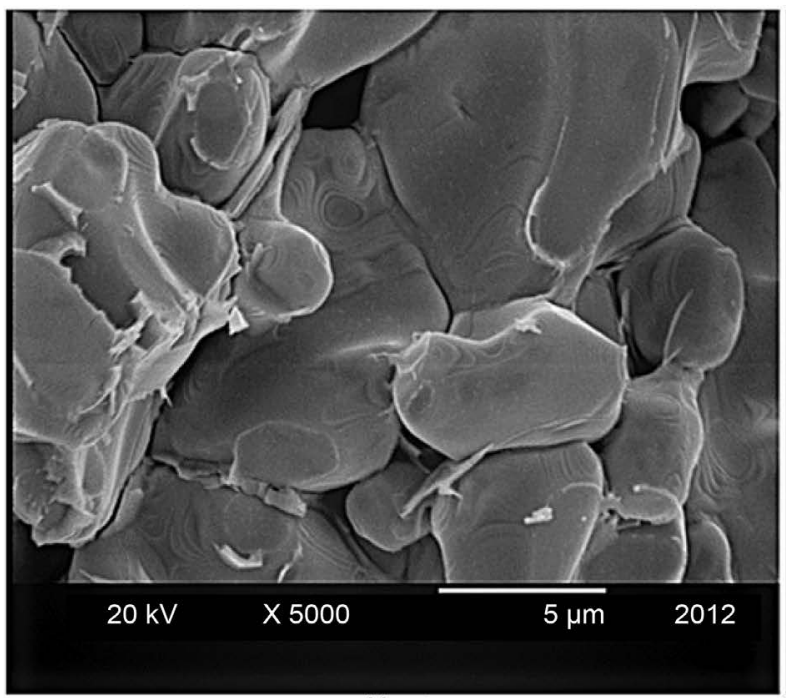

$X=0$

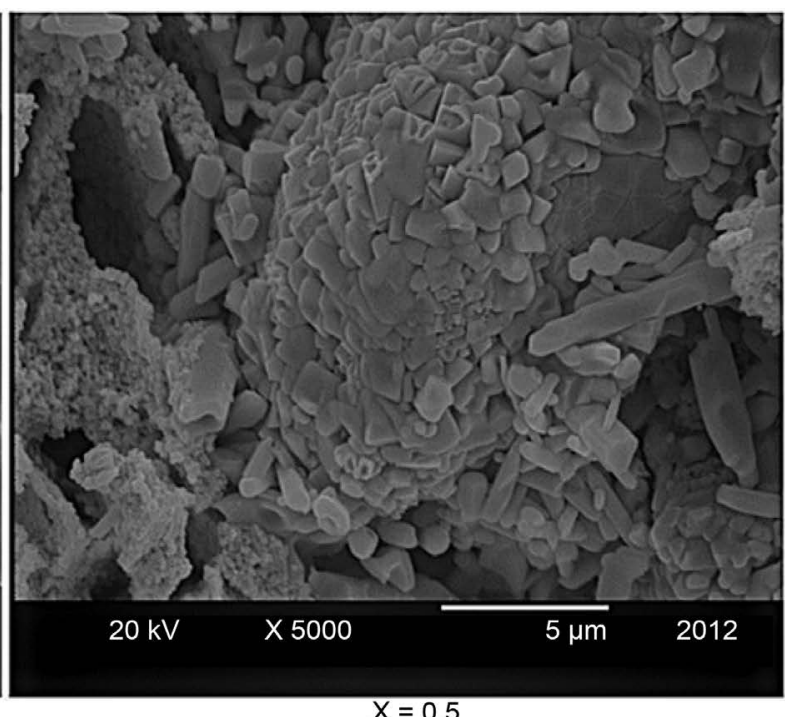

(b)

Figure 3. (a) SEM of co-precipitation $\mathrm{Pb}_{1-\mathrm{x}} \mathrm{Ni}_{\mathrm{x}} \mathrm{TiO}_{3}$ samples; (b) SEM of ceramic $\mathrm{Pb}_{1-\mathrm{x}} \mathrm{Ni}_{\mathrm{x}} \mathrm{TiO}_{3}$ samples.

ceramic samples and nano polycrystalline samples prepared by co-precipitation method. It is obvious that the increase of Ni content decrease the particle and grain size. This is due to the following: $\mathrm{Ni}^{2+}$ ions enter the lattice and replace some lead ions $\left(\mathrm{Pb}^{2+}\right)$. These doped ions precipitate at grain boundaries and retard its motions. The increase of $\mathrm{Ni}^{2+}$ ions inhabit the grain growth keeping the grain size small. Our explanation in similar to previous work [10], [11].

\subsection{Effect of Ni Content on the Piezoelectric Modulus $\mathrm{d}_{33}$}

The effect of Ni content on the piezoelectric modulus $d_{33}$ is shown in Figure 4. It is observed that $d_{33}$ of the polarized samples prepared by co-precipitation method are higher than those prepared by ceramic method. Doping ions concentrate near the domain boundaries in which some dislocations might act as precipitating centers for migration 


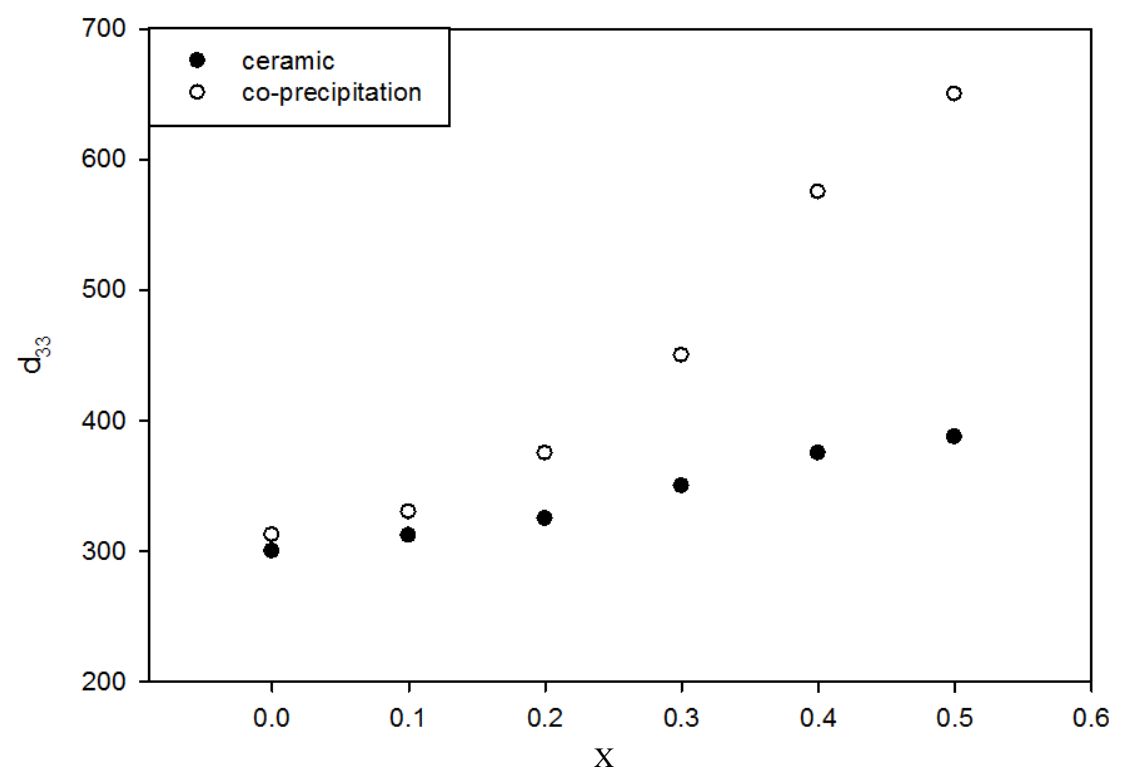

Figure 4. The piezoelectric coefficient $\mathrm{d}_{33}$ of " $\mathrm{Pb}_{1-\mathrm{x}} \mathrm{Ni}_{\mathrm{x}} \mathrm{TiO}_{3}$ " for ceramic and co-precipitation methods.

of these ions, which in turn act as pinning points causing further dislocations. Also the coulomb attraction between the doping ions and the induced vacancies leads to continuous formation of more lattice vacancies since many of them might act as sinks for these point defects.

Thus, the domain walls are expected be quite free in smaller particle size and grain size considering that grain boundaries will give additional pinning points to the moving walls. The beneficial result of the reduction in grain boundary is the decrease in coupling effect between boundaries and the domain walls leading to increase in domain wall mobility.

This mechanism may affect domain wall motion towards the increase of polarization and hence the observed increase of $d_{33}$ and generated piezoelectric charges under applied stress. More ever the $\mathrm{d}_{33}$ of nanoparticles of co-precipitation method is higher due to smaller area of grain boundaries compared to those in the samples prepared by ceramic method. This small area helpe the domain wall mobility to be increased giving rise to polarization under applied stresses. The behavior of our results are similar to those in previous work on lead titanate zirconate ceramics [12], [13].

\subsection{Electromechanical Coupling Factor $\boldsymbol{k}_{p}$}

The planer-coupling factor $k_{p}$, as a function of $\mathrm{Ni}$ dopant is shown in Figure 5. for the prepared polarized tablets by usual ceramic and co-precipitation method. As Ni additions increases, $k_{p}$ increases. This can be explained as follows:

$\mathrm{Ni}^{3+}$ substituted $\mathrm{pb}^{2+}$ sites of the perovskite tetragonal structure. For each $\mathrm{pb}^{2+}$ cation replaced with $\mathrm{Ni}^{3+}$ that a vacancy is created to maintain the charge neutrality of the system. It is in the tetragonal polarized ferroelectric materials, two types of domains are 


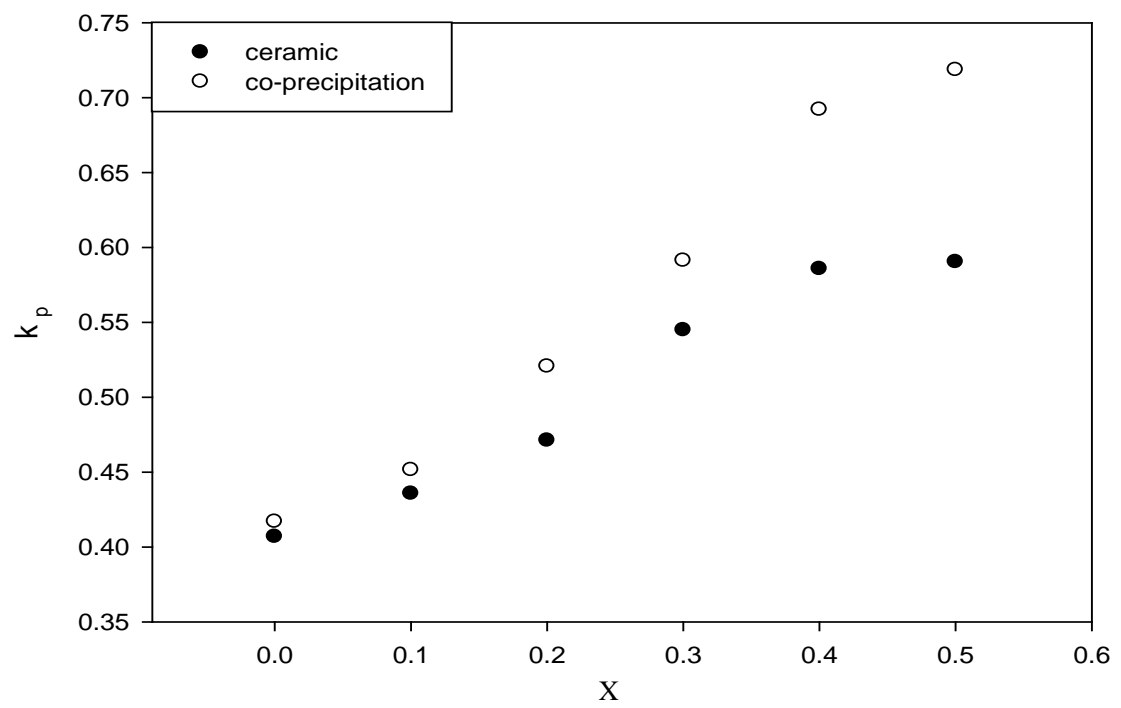

Figure 5. Effect of " $\mathrm{Pb}_{1-\mathrm{x}} \mathrm{Ni}_{\mathrm{x}} \mathrm{TiO}_{3}$ " on the coupling factor $k_{p}$ for ceramic and co-precipitation methods.

existed, $90^{\circ}$ and $180^{\circ}$ domains. The $180^{\circ}$ domains remain entirely after poling process, and small percentage of $90^{\circ}$ domains oriented in its position after poling. When ac field applied to the resonator (disc). The existence of lattice vacancies facilities to these domains to be vibrated at lower frequency [12]. This led to decrease the resonance frequency of the polarized tablets. The increase of Ni content increases the lattice vacancies caused the decrease of resonance frequency giving rise to $k_{p}$.

The increase of $k_{p}$ in the nano $\mathrm{Pb}_{1-\mathrm{x}} \mathrm{Ni}_{\mathrm{x}} \mathrm{TiO}_{3}$ polarized discs than those prepared by usual ceramic method is due to the lower grain boundary area which facilitate the domain wall motion under applied ac field. This lead to increase $k_{p}$ of the nano disc of $\mathrm{Pb}_{1-\mathrm{x}} \mathrm{Ni}_{\mathrm{x}} \mathrm{TiO}_{3}$. From Table 2 it is noticed that the particle size of the co-precipitation method is smaller for the usual ceramic in all $\mathrm{Ni}$ contents. $\mathrm{Ni}^{3+}$ ions enter the lattice instead of $\mathrm{pb}^{2+}$ ions. The small area of grain boundary of the nanoparticle of the co-precipitation method helped the domains wall mobility to be increased. This led to increase the piezoelectric characteristic properties in the nano crystallite of the co-precipitation method than those prepared by usual ceramic method.

\subsection{Effect of Ni Contents on the Ultrasonic Velocity}

Figure 6 illustrates the effect of $\mathrm{Ni}$ content on the velocity of ultrasonic wave for the radial mode of vibrating polarized tablets. It is obvious that the velocity decreases with increasing $\mathrm{x}$. This could be explained as following:

The velocity of sound wave for poled $\mathrm{Pb}_{1-\mathrm{x}} \mathrm{Ni}_{\mathrm{x}} \mathrm{TiO}_{3}$ of the two method of preparation can be evaluated in the radial mode may be due to the following:

The decrease in sound wave velocity with doping may be due to the creation of lead vacancies. These vacancies help the domain wall to vibrate early leading to decreases the ultrasonic wave velocity. Our explain is in close to previous work on PZT [11]. 
Table 2. $k_{p}$ and $\mathrm{d}_{33}$ of the published data and our present data.

\begin{tabular}{|c|c|c|c|}
\hline composition & $k_{p}$ & $\mathrm{~d}_{33}(\mathrm{PC} / \mathrm{N})$ & \\
\hline $\mathrm{PbTiO}_{3}$ & 0.3 & 56 & [14], [15] \\
\hline $\mathrm{BaTiO}_{3}$ & 0.35 & 191 & {$[16]$} \\
\hline PZT:Nb & 0.54 & - & {$[17]$} \\
\hline PZT:(La + Nb) & 0.57 & - & {$[17]$} \\
\hline PZT & 0.32 & 220 & {$[18]$} \\
\hline Pure PZT (52/48) & 0.47 & - & {$[18]$} \\
\hline $\mathrm{Pb}\left(\mathrm{Zr}_{0.52}, \mathrm{Ti}_{0.48}\right) \mathrm{O}_{3}$ & 0.53 & 223 & {$[16]$} \\
\hline $\mathrm{Pb}_{0.9725}\left(\mathrm{Zr}_{0.52} \mathrm{Ti}_{0.48}\right)_{0.945} \mathrm{Nb}_{0.055} \mathrm{O}_{3}$ & 0.59 & 386 & [19] \\
\hline PZT:Sr & 0.52 & - & {$[20]$} \\
\hline BZT-50BCT & 0.5 & 546 & {$[21]$} \\
\hline PZT5A & 0.6 & 374 & {$[21]$} \\
\hline PZT:Mg & 0.381 & - & {$[22]$} \\
\hline PZT:Zr & 0.446 & - & {$[22]$} \\
\hline $\mathrm{Pb}_{0.9} \mathrm{Ni}_{0.1}\left(\mathrm{Zr}_{0.52}, \mathrm{Ti}_{0.48}\right) \mathrm{O}_{3}$ & - & 121 & [10] \\
\hline $\mathrm{Pb}\left(\mathrm{Mn}_{1 / 3} \mathrm{Nb}_{2 / 3}\right) \mathrm{O}_{3}$ & 0.45 & - & [23] \\
\hline $0.5\left(0.1 \mathrm{BiYbO}_{3}-0.9 \mathrm{PbTiO}_{3}\right)-0.5 \mathrm{~Pb}\left(\mathrm{Zn}_{1 / 3} \mathrm{Nb}_{2 / 3} \mathrm{O}_{3}\right)(\mathrm{BYPT}-\mathrm{PZN})$ & 0.23 & 85 & {$[24]$} \\
\hline $\mathrm{Pb}_{1-3 \mathrm{x} / 2} \mathrm{Fe}_{\mathrm{x}}\left(\mathrm{Zr}_{0.52} \mathrm{Ti}_{0.48}\right)_{1-5 \mathrm{y} / 4} \mathrm{Nb}_{\mathrm{y}} \mathrm{O}_{3}(\mathrm{PFZTN})$ & $\longrightarrow$ & 300 & {$[25]$} \\
\hline $\mathrm{Pb}_{0.95} \mathrm{Bi}_{0.03} \mathrm{Nb}_{0.02} \mathrm{Zr}_{0.51} \mathrm{Ti}_{0.49}-\mathrm{xM}_{\mathrm{x}} \mathrm{O}_{3}$ & 0.665 & $625(\mathrm{pm} / \mathrm{V})$ & [26] \\
\hline Nano $\mathrm{Pb}_{0.5} \mathrm{Ni}_{0.5} \mathrm{TiO}_{3}$ crystallite & 0.73 & 650 & Present work \\
\hline
\end{tabular}

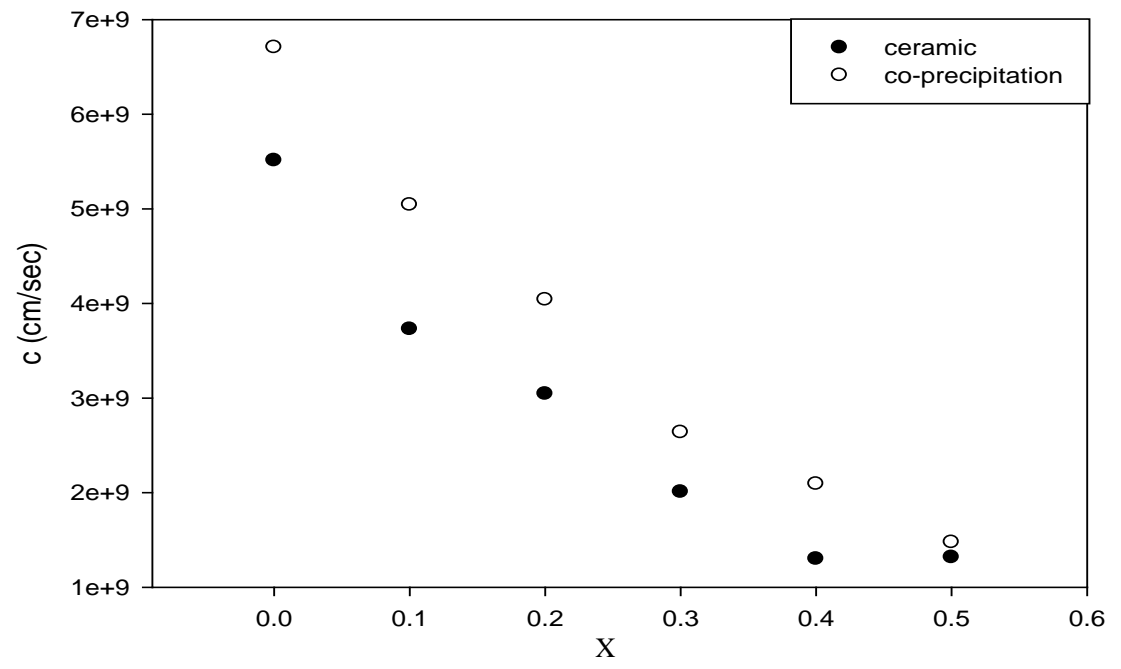

Figure 6. Effect of $\mathrm{x}$ on ultrasonic velocity for ceramic and co-precipitation methods.

\section{Conclusions}

In this paper, the piezoelectric $\mathrm{d}_{33}$ for the $\mathrm{Pb}_{1-\mathrm{x}} \mathrm{Ni}_{\mathrm{x}} \mathrm{TiO}_{3}$ ceramics prepared by co-pre- 
cipitation method were found to be higher than those prepared by ceramic method. This caused by inhibition of grain wall volume.

The increase of $k_{p}$ for samples prepared by co-precipitation method was due to entering $\mathrm{Ni}$ ions the lattice and substitute $\mathrm{Pb}^{2+}$ ions. This caused creation of vacancies. These vacancies helped the dipoles to vibrate at lower frequency.

The decrease of ultrasonic waves with enhancing Ni contents was due to creation of vacancies, which scattered the propagation of the waves.

It is clearer the present sample $\mathrm{Pb}_{0.5} \mathrm{Ni}_{0.5} \mathrm{TiO}_{3}$ possessed higher $\mathrm{d}_{33}$ and $k_{p}$ than those in previous work [12] which is useful in technology.

\section{References}

[1] Yamashita, Y., Yokoyama, K., Honda, H. and Takahashi, T. (1981) (Pb, Ca) $\left(\left(\mathrm{Co}_{1 / 2} \mathrm{~W}_{1 / 2}\right)\right.$, $\mathrm{Ti}) \mathrm{O}_{3}$ Piezoelectric Ceramics and Their Applications. Japanese Journal of Applied Physics, 20, 183-187. http://dx.doi.org/10.7567/JJAPS.20S4.183

[2] Takahashi, T. (1990) Lead Titanate Ceramics with Large Piezoelectric Anisotropy and Their Application. American Ceramic Society Bulletin, 69, 691-695.

[3] Hashimoto, K., Tsuruta, T., Morinaka, K. and Yoshiike, N. (2000) High Performance Human Information Sensor. Sensors and Actuators A: Physical, 79, 46-52.

http://dx.doi.org/10.1016/S0924-4247(99)00247-2

[4] Suwannasiri, T. and Safari, A. (1993) Modified Lead Titanate Ceramics. Journal of the American Ceramic Society, 76, 3155-3158. http://dx.doi.org/10.1111/j.1151-2916.1993.tb06623.x

[5] Chu, S.Y. and Chen, C.H. (2001) Effect of Calcium on the Piezoelectric and Dielectric Properties of Sm-Modified $\mathrm{PbTiO}_{3}$ Ceramics. Sensors and Actuators A: Physical, 89, 210 214. http://dx.doi.org/10.1016/S0924-4247(00)00536-7

[6] Ricote, J., Alemany, C. and Pardo, L. (1995) Microstructural Effects on Dielectric and Piezoelectric Behavior of Calcium-Modified Lead Titanate Ceramics. Journal of Materials Research, 10, 3194-3203. http://dx.doi.org/10.1557/JMR.1995.3194

[7] Troilo, L.M., Damjanovic, D. and Newnham, R.E. (1994) Modified Lead Calcium Titanate Ceramics with a Relatively Large Dielectric Constant for Hydrophone Applications. Journal of the American Ceramic Society, 77, 857-859. http://dx.doi.org/10.1111/j.1151-2916.1994.tb05380.x

[8] Kellati, M., Sayouri, S., El-Moudden, N., Elaatmani, M., Kaal, A. and Taibi, M. (2004) Structural and Dielectric Properties of La-Doped Lead Titanate Ceramics. Materials Research Bulletin, 39, 867-872. http://dx.doi.org/10.1016/j.materresbull.2004.01.003

[9] Jiang, S.L., Zhang, X.L., Wang, X.Z. and Wang, X.H. (1995) Investigation on Anisotropy in Piezoelectric Properties of Modified $\mathrm{PbTiO}_{3}$ Ceramics. Piezoelect. Acoust., 17, 26-29.

[10] Kumari1, N., Singh, A. and Mandal, J. (2013) Lead Zirconate Titanate Piezoelectric Ceramics with Nickel Oxide Additions. International Refereed Journal of Engineering and Science, 2, 51-55.

[11] Atikin, R.B. and Fulrath, R.M. (1971) Point Defects and Sintering of Lead Zirconate-Titanate. Journal of the American Ceramic Society, 54, 265-270. http://dx.doi.org/10.1111/j.1151-2916.1971.tb12286.x

[12] Tawfik, A. (1985) Elastic Properties and Sound Wave Velocity of PZT Transducers Doped with Ta and La. Journal of the American Ceramic Society, 68, 317-319. http://dx.doi.org/10.1111/j.1151-2916.1985.tb10132.x 
[13] Ahd El-Salam, F., Tawfik, A. and Eatah, A.I. (1983) Effect of Li Loss on Some Physical Properties of Al-Li Alloy. Physica Status Solidi A, 75, 379-384.

http://onlinelibrary.wiley.com/doi/10.1002/pssa.2210750205/abstract

[14] Ikegami, S., Ueda, I. and Nagata, T. (1971) Electromechanical Properties of $\mathrm{PbTiO}_{3}$ Ceramics Containing La and Mn. The Journal of the Acoustical Society of America, 50, 1060-1066. http://dx.doi.org/10.1121/1.1912729

[15] Damjanovic, D., Gururaja, T.R. and Cross, L.E. (1987) Anisotropy in Piezoelectric Properties of Modified lead Titanate Ceramics. American Ceramic Society Bulletin, 66, 699-703.

[16] Jaffe, B., Cook, W.R. and Jaffe, H. (1971) Piezoelectric Ceramics, Vol. 3. Non-Metallic Solids. Academic Press, London.

[17] Kulcsa, F. (1959) Electromechanical Properties of Lead Titanate Zirconate Ceramics Modified with Certain Three-or Five-Valent Additions. Journal of the American Ceramic Society, 42, 343-349. http://dx.doi.org/10.1111/j.1151-2916.1959.tb14321.x

[18] Flynn, A.M. (1997) MIT Artificial Intelligence Laboratory, Cambridge, 25.

[19] Chu, S.Y., Chen, T.Y., Ta Tsai, I. and Water, W. (2004) Doping Effects of Nb Additives on the Piezoelectric and Dielectric Properties of PZT Ceramics and Its Application on SAW Device.. Sensors and Actuators A, 113.

[20] Chen, X.M. and Yang, J.S. (1998) Toughening of PZT Piezoelectric Ceramics by In-Situ Complex Structures. Journal of the European Ceramic Society, 18, 1059-1062. http://dx.doi.org/10.1016/S0955-2219(97)00199-4

[21] Tung, V.T., Tinh, N.T., Yen, N.H. and Tuan, D.A. (2013) Evaluation of Electromechanical Coupling Factor for Piezoelectric Materials Using Finite Element Modeling Title. International Journal of Materials and Chemistry, 3, 59-63.

[22] Tajima, K., Hwang, H.J., Sando, M. and Niihara, K. (1999) PZT Nanocomposites Reinforced by Small Amount of Oxides. Journal of the European Ceramic Society, 19, 11791182. http://dx.doi.org/10.1016/S0955-2219(98)00399-9

[23] Nadoliisky, M.M. and Vasileva, T.K. (2007) Dielectric and Piezoelectric Properties of a Triple Ferroceramics System $\mathrm{PbTiO}_{3}-\mathrm{PbZrO}_{3}-\mathrm{Pb}\left(\mathrm{Mn}_{1 / 3} \mathrm{Nb}_{2 / 3}\right) \mathrm{O}_{3}$. Bulgarian Journal of Physics, 34, 71-76.

[24] Shi, L., Liao, Q., Zhang, B., Zhang, J. and Guo, D. (2014) Structure and Electrical Properties of $(1-\mathrm{x})\left(0.1 \mathrm{BiYbO}_{3}-0.9 \mathrm{PbTiO}_{3}\right)-\mathrm{xPb}\left(\mathrm{Zn}_{1 / 3} \mathrm{Nb}_{2 / 3}\right) \mathrm{O}_{3}$ High-Temperature Ternary Piezoelectric Ceramics. Materials Letters, 114, 100-102. http://dx.doi.org/10.1016/j.matlet.2013.09.061

[25] Kumar, A. and Mishra, S.K. (2014) Structural and Dielectric Properties of Nb and Fe CoDoped PZT Ceramic Prepared by a Semi-Wet Route. Advanced Materials Letters, 5, 479484. http://dx.doi.org/10.5185/amlett.2014.564

[26] Miclea, C., Tanasoiu, C., Miclea, C.F., Gheorghiu1, A. and Sima, F.N. (2005) Effect of Iron and Nickel Substitution on the Piezoelectric Properties of PZT Type Ceramics. Journal of the European Ceramic Society, 25, 2397-2400.

http://dx.doi.org/10.1016/j.jeurceramsoc.2005.03.069 
Submit or recommend next manuscript to SCIRP and we will provide best service for you:

Accepting pre-submission inquiries through Email, Facebook, LinkedIn, Twitter, etc. A wide selection of journals (inclusive of 9 subjects, more than 200 journals)

Providing 24-hour high-quality service

User-friendly online submission system

Fair and swift peer-review system

Efficient typesetting and proofreading procedure

Display of the result of downloads and visits, as well as the number of cited articles

Maximum dissemination of your research work

Submit your manuscript at: http://papersubmission.scirp.org/

Or contact jamp@scirp.org 